\title{
EXPERIMENTAL EVALUATION OF THE EFFECT OF SILICA FUME ON COMPRESSIVE, TENSILE STRENGTH, ABRASION RESISTANCE, SLUMP AND IMPACT TEST AND WATER PERMABILITY COEFFICIENT OF CONCRETE
}

\author{
M. Esmailpour ${ }^{\text {a }}$, K. Rahmani ${ }^{\text {a*}}$, S. Piroti ${ }^{\text {a }}$ \\ ${ }^{a}$ Department of Civil Engineering, Mahabad Branch, Islamic Azad University, Mahabad, Iran, \\ e-mails: mohandes_so@yahoo.com,*ostad_so@yahoo.com, s.piroti@iau-mahabad.ac.ir
}

Received: 20.03.2018 / Accepted: 02.04.2018 / Revised: 15.04.2018 / Available online: 31.05.2018

DOI: 10.2478/jaes-2018-0004

KEY WORDS: Concrete, Microsilica, Mechanical properties, Slump.

\begin{abstract}
:
The use of various additives (admixtures) in concrete and cement products has been considered by various researchers in recent years. Microsilica (Silica fume) can also be considered as one of the most widely used additives (admixtures) in this section. In this study, 120 concrete specimens were constructed using a mix design based on ACI in the laboratory with an overview of records and advantages of using microsilica in concrete. The microsilica used in concrete specimens has been considered $2 \%, 5.5 \%$ and $7.5 \%$ by weight of cement. Finally impact permeability, tension and uniaxial compressive strength tests were done on concrete specimens and their mechanical properties were evaluated. The results show that microsilica improves the mechanical properties of concrete. The results also show that the use of microsilica in ordinary concrete has a very positive effect in controlling the surface cracks and increasing some strength parameters such as tensile and compressive strength of concrete.
\end{abstract}

\section{INTRODUCTION}

Considering the advances in science and technology in the recent century, the development of science of knowing concrete types and their properties has also been remarkable, so nowadays different types of concrete with different materials are produced and used. Any combined concrete technology with microsilica is another example of the use of admixtures as a new technology in the construction industry. Microsilica is a substance that is produced from silica and collected in powder form by special filters. About $85 \%$ of its particles consists of silicon, aluminum, iron, calcium and magnesium oxides (Genadij and Juris, 1998).

The desirable effects of this material on improvement of fresh and hardened concrete properties has led to its increasing consumption in the world. The use of this material increases the workability of fresh concrete. The lower permeability, proper action against carbonation phenomenon, sulfate and chloride resistance, and control of Alkali-Aggregate Reaction (ARR) are the advantages of using this material instead of cement. Although, all the mentioned advantages are affected by the proper selection of water cement ratio, adequate curing, desirable quality of microsilica and the appropriate amount of microsilica instead of cement. If the specifications of this material conform to the standard requirements, the replacement value of $20 \%$ to $50 \%$ will be a good choice, however in some cases higher values are used (Rahmani et.at, 2018).

Since microsilica is a modern industrial material that is made from coal residues, its research and application in concrete has not a long history. In this section, we refer to the following records:

Newlon (1976) investigated the use of $8 \%$ charcoal microsilica for concrete mix design of bridge deck. Finally, $10 \%$ microsilica instead of cement weight was proposed as the best option. Mehta (1991) made a combination of the use of silica fume and microsilica to economize the mass concrete placing over the years. The most important parameter in addition to the economic aspect was the improvement of compressive strength of concrete. Kwan and More (2005) investigated the effect of $\mathrm{PH}$ as a harmful factor on charcoal microsilica concrete.

Carter and Yan (2005) investigated the effect of microsilica as a filler and to reduce the water consumption in concrete. Lee et al. (2005) examined the hydration and curing of microsilica concrete. Torii and Kawamura (1994) investigated the use of water with $\mathrm{PH}$ from 10.5 to 12.5 on the strength of concrete containing high volume microsilica. Many studies have been done for expressing the relationship between the compressive strength of cement with its effective chemical and physical properties recently (Faleschini et al., 2015, Ferrándiz-Mas et al., 
2016, Mármol et al., 2016). By presenting an experimental relationship between cement components and its fineness with compressive strength, cement can be produced by high quality and low energy. Zhang and $\mathrm{Li}$ (2013) performed an experimental study to investigate the combined effect of silica fume and polypropylene fiber on the workability and drying shrinkage of concrete composite containing fly ash. They concluded that the workability of the concrete composite becomes better and the drying shrinkage strain is decreasing gradually with the increase of fly ash content.

In recent years, many studies have been conducted in the mechanical characteristics of reinforced fiber concrete. Such concrete is used in retrofitting and repairing the covering of concrete structure tunnels, carpentries stabilizing, asphalts and etc. According to the researches, the increase of formability and bending strength are the extra advantages of adding the fibers to the concrete. Two kinds of fiber that very often used in the concrete are: steel fiber and polypropylene fiber (Mirsayar et.al. 2017; Jafari et.al. 2018). However, polypropylene fiber has a little adverse effect on the workability of concrete composite. Thus, polypropylene fiber, carbon fiber, plastic-glass based fiber and steel fibers had started to be used in concrete. It is known that steel, nylon and mixed fibers affect less the mechanical properties such as compressive strength and elasticity module, and highly increases the mechanical properties such as bending - tensile strength, ductility and toughness (Unterweger et al., 2014a, 2014b). Ozawa and Morimoto (2014) carried out permeability tests on high strength concretes ( $72 \mathrm{MPa}$ ) including $0.15 \%$ by volume of PPF. Results showed that the residual permeability increased 12 times after heating the PPF concrete to $500{ }^{\circ} \mathrm{C}$ compared to the reference concrete. Thus, the improvement of permeability which is increased and it reduces the likelihood of explosive spalling (Kodur, 2014). Rahmanzadeh et al. (2018) experimentally investigated the effect of water-cement ratio on abrasion resistance, porosity and hydraulic conductivity coefficient of Nano silica concrete. They showed that the compressive strength of concrete in a particular temperature is related to two factors: water-cement ratio and density. In their research, decreasing the water-cement ratio from 0.46 to 0.30 improved the abrasion resistance of Nano silica concrete by $42 \%$, the hydraulic conductivity coefficient of concrete decreased from $28.5 \times 10^{-15}$ to $1.7 \times 10^{-15} \mathrm{~m} / \mathrm{s}$ and the porosity of concrete decreased to $13.1 \%$. In addition, the abrasion depth increased gradually by increasing the water-cement ratio from 0.30 to 0.46 .

In this study, uniaxial compressive strength test has been done on concrete specimens and their mechanical properties and compressive strength are evaluated. The main purpose of this research is providing the necessary bases to provide a suitable and economical plan for the production of microsilica concrete to provide a basis for increasing the safety and being economical of designs in this field.

Since microsilica is a modern industrial material that is made from coal residues, its research and application in concrete has not a long history. In this section, we refer to the following records:

1. Explanation of the effect of changes in the volume and weight of microsilica for determining the ultimate compressive, flexural and tensile strength capacity of specimens.

2. Using mix design softwares based on ACI to provide a plan which can estimate the ultimate capacity of real-size specimens as close as possible to empirical results to be used as a basis for parametric researches on this field.

3 . Increasing the speed of construction, reliability and safety of structures against earthquakes and industrial development of building industry as a result.

4. Increase the ultimate strength capacity of specimens.

5. The ability to simulate real engineering processes with minimal simplifications.

Recognition of microsilica as a complementary component of concrete can help us to produce concrete with more favorable properties. The goals of this research are finding an empirical relationship between the amount of microsilica and mechanical properties of concrete. This study also examines the possibility of increasing the application and efficiency of microsilica in concrete by changing the cement and replacing it with microsilica as an admixture. The following topics are considered in this research:

1. Investigating the ratio of microsilica to cement content in calculation of compressive, flexural and tensile strength.

2. Investigation of slump and consistency changes in microsilica concrete compared to ordinary concrete.

3. Increasing the amount of microsilica in which models is optimal and economical.

\section{METHODOLOGY}

In this study the history and advantages of using microsilica in concrete are reviewed and the use of several mix designs for production of concrete specimens with the replacement of $2.5 \%$, $5 \%$ and $7.5 \%$ of cement weight with microsilica and the effects of this parameter on mechanical properties and slump of concrete are investigated. Mechanical properties of used materials are assessed according to ASTM. Type I Portland cement and drinking water are used to make the specimens in this research.

\subsection{Mix Design}

Various methods (of mix design) have been recommended by the regulations including ACI, PCA, B.S and dozens of other experimental mix designs. It should be noted that concrete mix design methods are based on properties of materials that are available in each region or country and, of course, their application in another area will not be accurate enough.

In this study, the concrete mix design is presented in accordance with the ACI-211 procedure by weighted method. The advantage of using this method is that in the final stages of design, by constructing a laboratory specimen and performing a few simple tests on it, the results of previous stages are corrected and thus the effect of special properties of materials is adequately involved in design results (Yazıc1, 2008; Song et. Al., 2007). The mix design used in this study is presented by weight in Table 1 . 
Table 1. Concrete mix design (ratios by weight)

\begin{tabular}{|c|c|c|c|c|c|}
\hline Cement & Water & Gravel & Sand & $\begin{array}{c}\text { Water } \\
\text { cement } \\
\text { ratio }\end{array}$ & $\begin{array}{c}\text { Plasticizer } \\
\text { by weight } \\
\text { of water }\end{array}$ \\
\hline $\mathrm{Kg} / \mathrm{m}^{3}$ & $\mathrm{Kg} / \mathrm{m}^{3}$ & $\mathrm{Kg} / \mathrm{m}^{3}$ & $\mathrm{Kg} / \mathrm{m}^{3}$ & $\%$ & $\%$ \\
\hline 390 & 195 & 702 & 1170 & 0.5 & 1 \\
\hline
\end{tabular}

\subsection{Abrasion resistance determining test (Los Angeles Abrasion Test)}

This test describes the method of determining the abrasion resistance of coarse-grained stone aggregates smaller than 37.5 $\mathrm{mm}$ by the Los Angeles machine. The Los Angeles test is done to measure the strength of mineral aggregates with standard grading against impact and abrasion. The Los Angeles machine is a rotary steel cylinder with a specified number of steel bullets in it. The number of bullets depends on the grading of test sample (Figure 1).

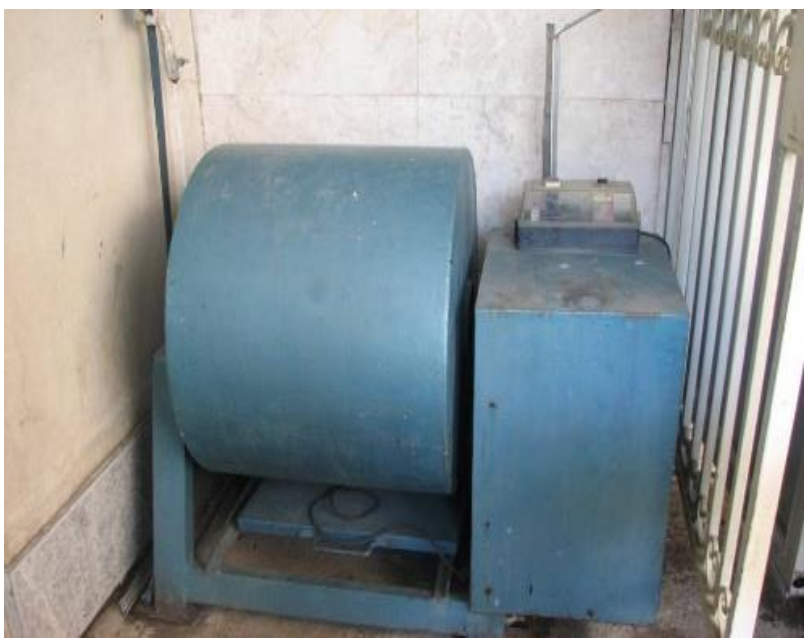

Figure 1. The Los Angeles Machine

The timer is adjusted to a speed of 30 to $33 \mathrm{rpm}$ (Revolutions per Minute) and to a maximum of 500 revolutions. After 500 revolutions (of aggregates and bullets in machine), the sample is removed from the machine slowly. Using the pan underneath the machine, materials are collected and passed through the No. $4(4.75 \mathrm{~mm})$ sieve firstly. Then the materials passing the No. 4 sieve are passed through the No. $12(1.7 \mathrm{~mm})$ sieve and from the total $5000 \pm 10$ grams aggregates, materials retained on the No. 12 sieve are completely washed and weighed after drying $\left(\mathrm{W}_{\mathrm{s}}\right)$.

\section{RESULTS AND DISCUSSION}

The abrasion percentage can be calculated from Equation (1). In addition the sample tested in this study was selected from the Table 2 .

$$
\text { Abrasion Percentage }=\frac{(5000 \pm 10)-W_{S}}{5000 \pm 10} \times 100
$$

Table 2. Properties of samples tested in this study (total mass of specimen: $5 \mathrm{~kg}$ )

\begin{tabular}{|c|c|c|c|}
\hline Sieve Size & $\begin{array}{c}\text { Retained } \\
\text { Weight (gr) }\end{array}$ & $\begin{array}{c}\text { Passed } \\
\text { Weight (gr) }\end{array}$ & $\begin{array}{c}\text { Percent } \\
\text { Passing }\end{array}$ \\
\hline 4 & 4222 & 704 & 14.08 \\
\hline 12 & 168 & 536 & 10.72 \\
\hline Under the sieve & 536 & 0 & 0 \\
\hline
\end{tabular}

Abrasion resistance of aggregates $=10.72 \%$

This experiment was carried out twice for an aggregate type. For the correctness and uniformity of aggregate hardness, firstly after 100 revolutions (without washing aggregate) and then after 500 revolutions, the abrasion percentage was calculated. In the analysis of results, if the abrasion ratio is less than 0.2 , the abrasion resistance of sample will be good and if it is more than 0.2 , the sample will not have a good abrasion resistance. According to ASTM, we should have:

Abrasion percentage for 500 revolutions

Abrasion percentage for100 revolutions $>0.2$

Percentage of passing the No.12 sieve for 100 revolutions

Percentage of passing the No.12 sieve for 500 revolutions $<0.2$

The sample has a good abrasion resistance

\subsection{Impact Test}

Several methods of impact test are used to investigate the impact strength of concrete and similar building materials. None of these experiments have been announced as standard tests. The ACI 544 Committee has proposed Drop Weight impact test to investigate the impact resistance of concrete. This test is used due to its simplicity in many cases. The proposed method by the ACI 544 Committee has been used to investigate the impact resistance of concrete in this study. The lower plate has been coated with grease to reduce the friction between the bottom plate and the specimen. 42 disc shaped specimens with a diameter of $15 \mathrm{~cm}$ and a thickness of $64 \mathrm{~mm}$ were tested according to the standard proposed method of ACI 544. In this method, a $4.5 \mathrm{~kg}$ hammer imposes sequential impacts on disc shaped specimens from a height of $45 \mathrm{~cm}$ (Figure 2). Two characteristics determine the impact resistance of specimens:

1. The number of impacts corresponding to the first visible crack.

2. The number of required impacts until final fracture, namely when the disc shaped concrete specimen touches three quarters of positioning lugs.

It was observed that specimens without microsilica were fractured after a small number of impacts while concrete specimens containing microsilica tolerate more impacts until ultimate fracture after initial cracking.

The amount of microsilica has a significant effect on the ultimate fracture of specimens and specimens containing a higher percentage of microsilica are fractured in a higher number of impacts. 
This resistance after initial cracking for reinforced concrete specimens containing $5 \%$ of microsilica has increased by $83 \%$ to $166 \%$ compared to control specimens. This parameter has also increased by $93 \%$ to $157 \%$ for reinforced $\mathrm{col} 35$ specimens with $7.5 \%$ of microsilica.

Figure 3 and 4 show the microsilica and control specimens after the impact test compared to each other. It can be seen that nonmicrosilica specimens (control specimens) have been divided into three separate parts after the impact test while in specimens containing microsilica, four fairly symmetrical cracks have been appeared and remained continuous due to the transfer of impact force and bridging between the cracks.

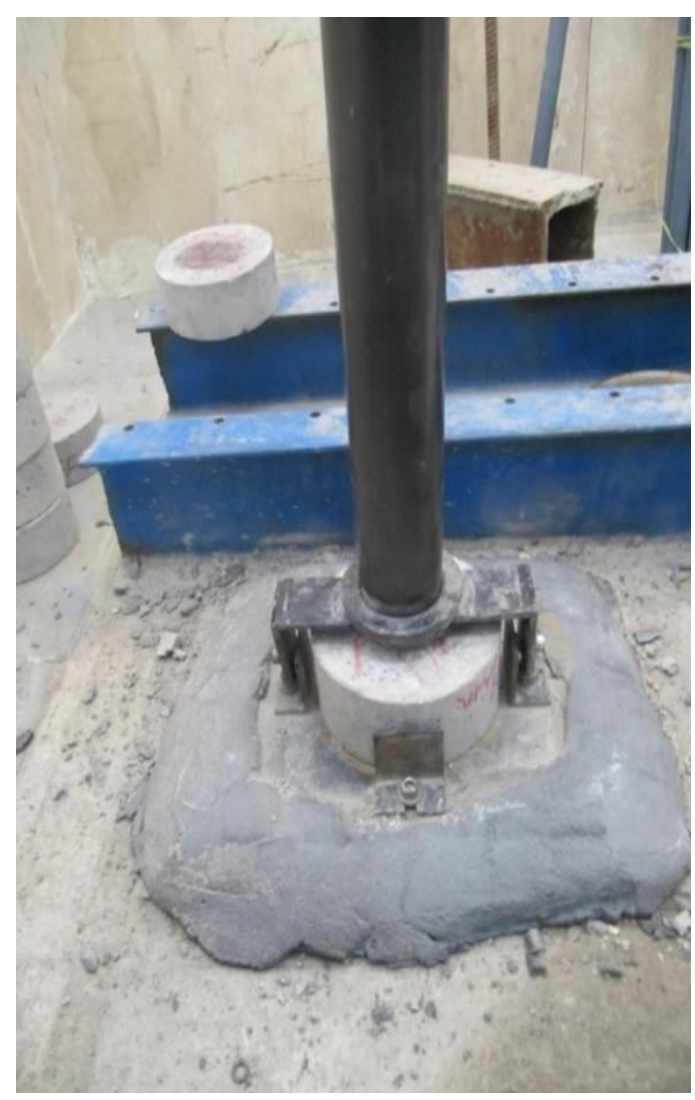

Figure 2. Impact test device

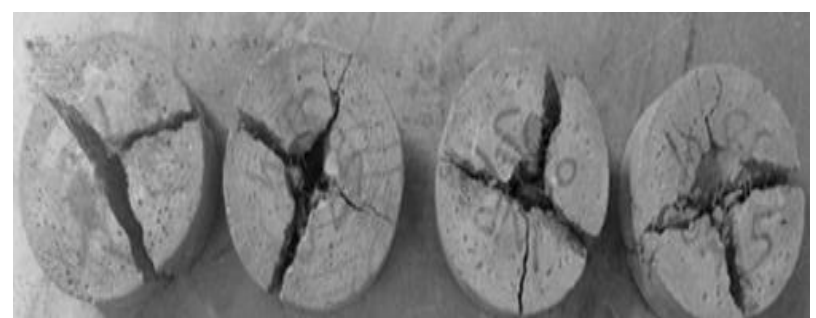

Figure 3. Specimens containing $5 \%$ of microsilica compared to the control specimen after the impact test

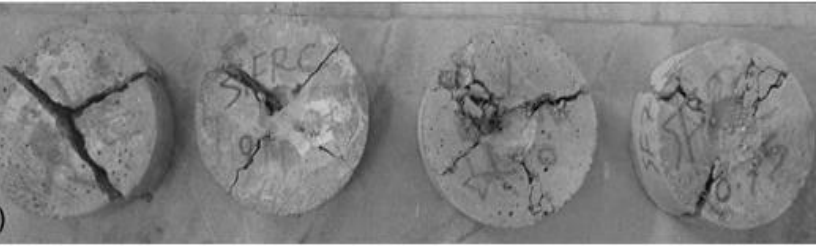

Figure 4. Specimens containing $7.5 \%$ of microsilica compared to the control specimen after the impact test

\subsection{Water permeability in concrete test}

Due to low permeability of concrete, the concrete permeability coefficient is calculated using Valenta's method which is based on the depth of penetration of fluid within the concrete specimen:

$$
k=\frac{x^{2} v}{2 T \Delta H}
$$

where $\quad k=$ water permeability coefficient $(\mathrm{m} / \mathrm{s})$

$x=$ penetration depth $(\mathrm{m})$

$v=$ the volume of cavities filled with water in the penetration part of water

$$
\begin{aligned}
& \Delta H=\text { the applied pressure (bar) } \\
& T=\text { time duration of specimen under pressure (s) }
\end{aligned}
$$

The value of $v$ represents distinct cavities such as air cavities which were not filled with water until the specimen was not under pressure and can be calculated from the increase in the mass of concrete during the permeability test. Note that only cavities in the part of the specimen that water has penetrated can be considered.

$$
k=\frac{\Delta W}{D A x} \quad, \quad \Delta W=W_{2}-W_{1}
$$

where $\Delta W=$ The amount of increase in the weight of specimen during the permeability test

$$
\begin{aligned}
& D=\text { Concrete density } \\
& A=\text { Cross section area of the specimen }
\end{aligned}
$$

The results obtained for the permeability using Valenta's method have been presented in the table. The amount of permeability for $2.5 \%, 5 \%$ and $7.5 \%$ of microsilica was decreased by $14.6 \%, 17.4 \%$ and $5.6 \%$, respectively compared to the control specimen. The minimum permeability coefficient was obtained in $7.5 \%$ of microsilica. It is also predicted that the curing time will be effective in reduction of permeability. Table 3 displays permeability coefficient of specimens using Valenta's relationship.

Table 3. Permeability coefficient of specimens using Valenta's relationship

\begin{tabular}{|c|c|}
\hline Permeability coefficient $(\mathrm{k})$ & Percentage of microsilica \\
\hline $1.23 \times 10^{-11}$ & 7.5 \\
\hline $1.19 \times 10^{-11}$ & 5 \\
\hline $1.36 \times 10^{-11}$ & 2.5 \\
\hline $1.44 \times 10^{-11}$ & - \\
\hline
\end{tabular}


Finally, the effect of increase in the percentage of microsilica on permeability and its changes with the mechanical properties of concrete was discussed. After testing the specimens and cutting them, the maximum penetration depth was approximately 2.6 centimeters and related to ordinary concrete. By examining other specimens, it can be seen that porosity and permeability decrease with increase in the percentage of microsilica in concrete. However, the specimen containing $7.5 \%$ of microsilica had the lowest permeability with $0.6 \mathrm{~cm}$ of penetration depth. Figure 5 illustrates cutting of cubic concrete specimens after the permeability test and water penetration depth in concrete specimens section.

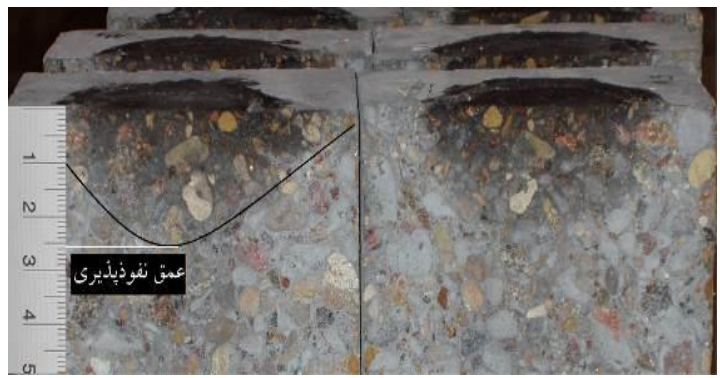

Figure 5. Water penetration depth in concrete specimens section

\subsection{Tensile test of specimens}

The tensile strength of specimens was calculated from the following equation:

$$
T=\frac{2 P}{\pi L D}
$$

Where $\quad T=$ Tensile stress $(\mathrm{MPa})$

$P=$ Maximum applied load on specimens by device

$(\mathrm{KN})$

$$
\begin{aligned}
& L=\text { Length of specimen }(\mathrm{mm}) \\
& D=\text { diameter of specimen }(\mathrm{mm})
\end{aligned}
$$

Figure 6 schematically shows how the specimens are loaded in indirect tension test and Figure 7 shows tensile test device.

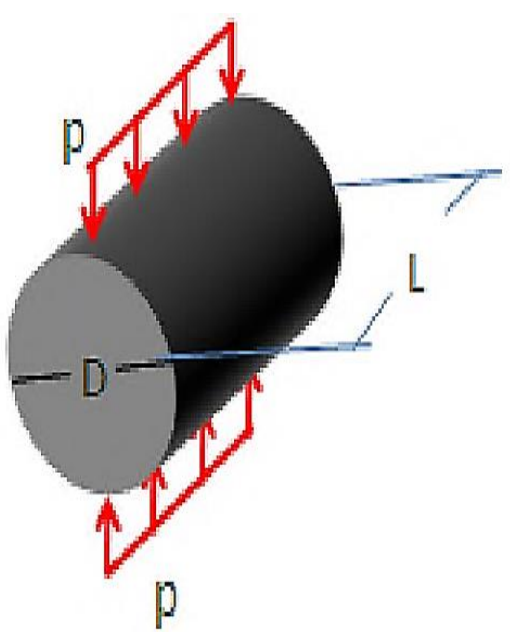

Figure 6. Loading of specimens in indirect tension test

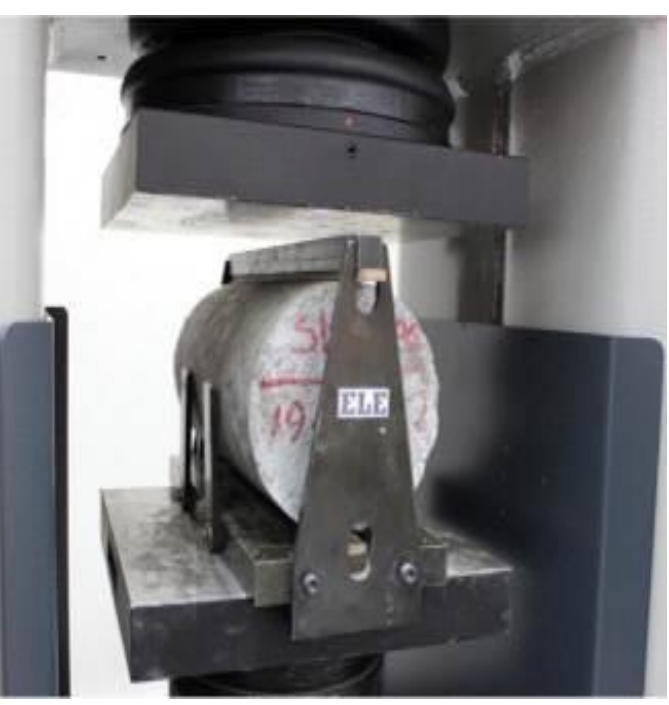

Figure 7. Tensile test method

Twelve cylindrical specimens with diameter of $15 \mathrm{~cm}$ and height of $30 \mathrm{~cm}$ were tested by indirect tension method (Brazilian Test) according to ASTM C496 standard. The results are presented in Table 4. Figures 8 and 9 show the tensile fracture of ordinary and reinforced with microsilica concrete specimens after tensile test respectively. It is evident that specimens without microsilica have been divided into two pieces after tensile test while in specimens containing microsilica, the crack opening width along the longitudinal direction of cylindrical specimen is less and indirect due to the presence of microsilica. In addition, it can be seen from Figure 10 that concrete tensile strength increases by adding a higher percentage of microsilica. The tensile strength of concrete increased by $25 \%$ and $41 \%$ (compared to control specimens) by adding $5 \%$ and $7.5 \%$ of microsilica by weight of cement

\begin{tabular}{|c|c|c|c|c|}
\hline Specimens & $\begin{array}{l}\text { Percentage } \\
\text { of } \\
\text { Microsilica }\end{array}$ & $\begin{array}{c}\text { Maximum } \\
\text { Applied } \\
\text { Load } \\
(\mathrm{KN})\end{array}$ & $\begin{array}{c}\text { Tensile } \\
\text { Stress } \\
(\mathrm{MPa})\end{array}$ & $\begin{array}{c}\text { Mean } \\
\text { Tensile } \\
\text { Stress } \\
(\mathrm{MPa}) \\
\end{array}$ \\
\hline SF1 & 0 & 65.9 & 2.03 & \multirow[t]{3}{*}{2.07} \\
\hline SF2 & 0 & 63.8 & 1.97 & \\
\hline SF3 & 0 & 71.2 & 2.2 & \\
\hline SF4 & 2.5 & 82.1 & 2.53 & \multirow[t]{3}{*}{2.38} \\
\hline SF5 & 2.5 & 78.7 & 2.43 & \\
\hline SF6 & 2.5 & 70.4 & 2.17 & \\
\hline SF7 & 5 & 83.3 & 2.57 & \multirow[t]{3}{*}{2.60} \\
\hline SF8 & 5 & 78.9 & 2.43 & \\
\hline SF9 & 5 & 91 & 2.81 & \\
\hline SF10 & 7.5 & 95.3 & 2.94 & \multirow[t]{3}{*}{2.92} \\
\hline SF11 & 7.5 & 99.2 & 3.06 & \\
\hline SF12 & 7.5 & 89.6 & 2.76 & \\
\hline
\end{tabular}
respectively.

Table 4. Tensile strength of specimens at an age of 28 days 


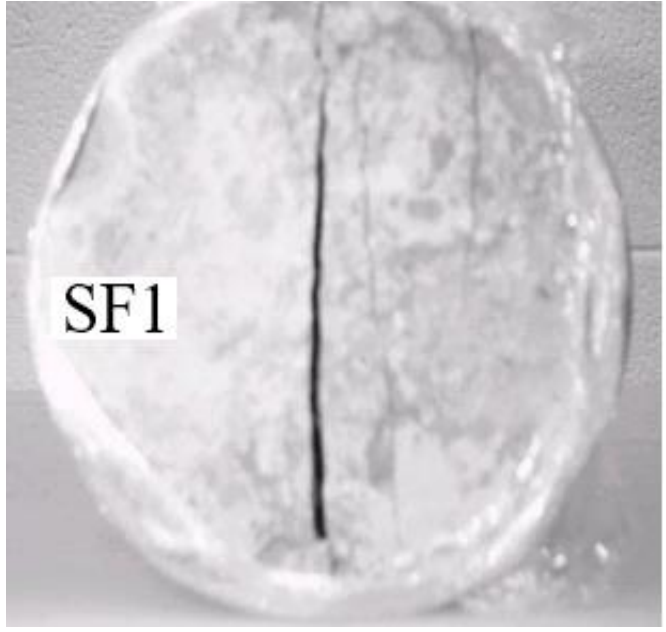

Figure 8. Tensile fracture of a specimen without microsilica

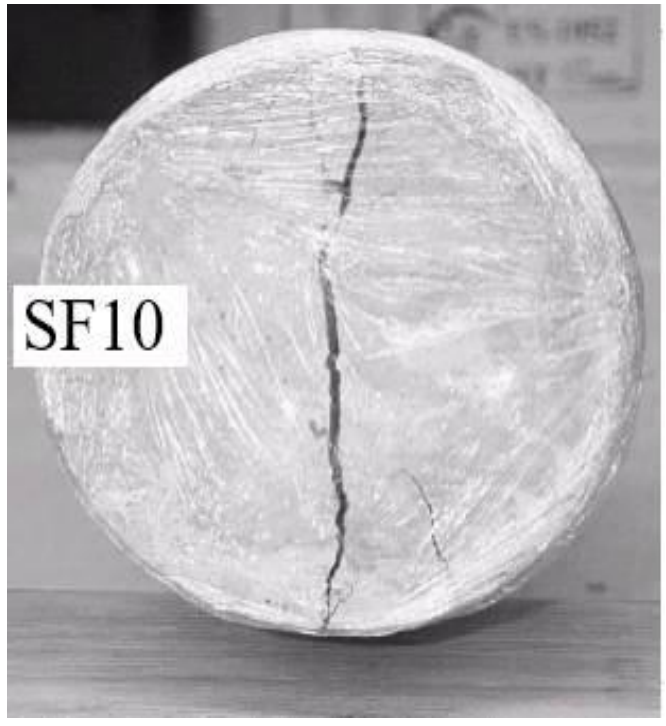

Figure 9. Tensile fracture of a specimen containing $7.5 \%$ of microsilica

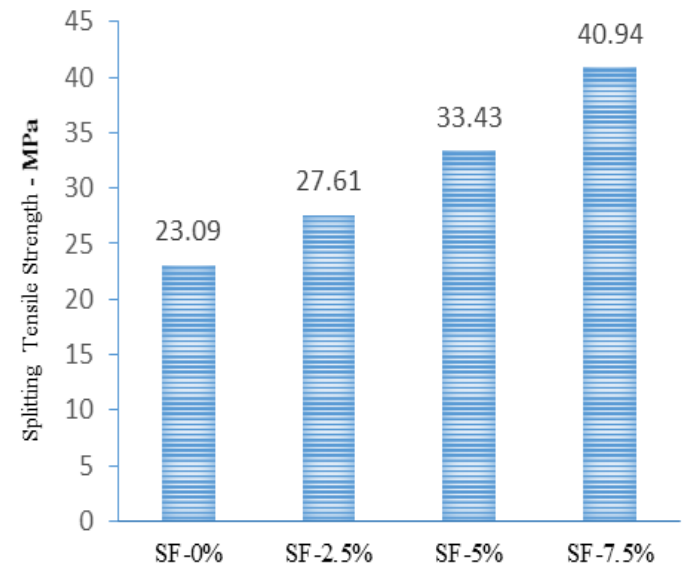

Figure 10. Concrete tensile strength versus the percentage of microsilica in specimens

\subsection{Compressive strength test}

The compressive strength of specimens was calculated from the following equation:

$$
F=\frac{4 P}{\pi D^{2}}
$$

where $\quad F=$ Compressive stress (MPa)

$P=$ Maximum applied load on specimens by device

$(\mathrm{KN})$

$$
D=\text { diameter of specimen }(\mathrm{mm})
$$

Figure 11 schematically shows how the specimens are loaded in indirect compression test. The results for this test have been summarized in Table 5. According to obtained results, the compressive strength of concrete increases by adding a higher percentage of microsilica. The compressive strength of concrete increased by $21 \%$ and $22.5 \%$ (compared to control specimens) by adding $5 \%$ and $7.5 \%$ of microsilica by weight of cement respectively. Figure 12 shows the compressive-shear fracture of ordinary and reinforced with microsilica concrete specimens after uniaxial compressive test.

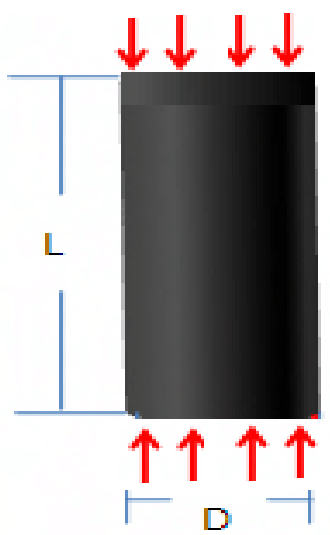

Figure 11. Loading of specimens in direct compression test

Table 5. Compressive strength of specimens at an age of 28

\begin{tabular}{|c|c|c|c|c|c|}
\hline Specimens & $\begin{array}{l}\text { Microsilica } \\
\text { Percentage }\end{array}$ & $\begin{array}{l}\text { Slump } \\
(\mathrm{mm})\end{array}$ & $\begin{array}{c}\text { Maximum } \\
\text { Applied } \\
\text { Load } \\
(\mathrm{KN})\end{array}$ & $\begin{array}{l}\text { Compressive } \\
\text { Stress (MPa) }\end{array}$ & $\begin{array}{c}\text { Mean } \\
\text { Compressive } \\
\text { Stress (MPa) }\end{array}$ \\
\hline SF1 & 0 & \multirow[t]{3}{*}{85} & 187.2 & 23.09 & \multirow[t]{3}{*}{23.13} \\
\hline SF2 & 0 & & 190.6 & 23.51 & \\
\hline SF3 & 0 & & 184.7 & 22.78 & \\
\hline SF4 & 2.5 & \multirow[t]{3}{*}{73} & 223.5 & 27.57 & \multirow[t]{3}{*}{27.61} \\
\hline SF5 & 2.5 & & 219.9 & 27.12 & \\
\hline SF6 & 2.5 & & 228.2 & 28.15 & \\
\hline SF7 & 5 & \multirow[t]{3}{*}{56} & 276.1 & 34.06 & \multirow[t]{3}{*}{33.43} \\
\hline SF8 & 5 & & 266.2 & 32.84 & \\
\hline SF9 & 5 & & 270.8 & 33.40 & \\
\hline SF10 & 7.5 & \multirow[t]{3}{*}{42} & 334.6 & 41.27 & \multirow[t]{3}{*}{40.94} \\
\hline SF11 & 7.5 & & 330.9 & 40.82 & \\
\hline SF12 & 7.5 & & 330.3 & 40.74 & \\
\hline
\end{tabular}
days 
It is evident from Figures 13 and 14 that specimens without microsilica have been severely cracked and disintegrated after uniaxial compressive test while in specimens containing microsilica, the crack opening width along the longitudinal direction of cylindrical specimen and crack fracture depths are less due to the presence of microsilica. In addition, it can be seen from Figure 15 that concrete compressive strength increases by increasing the percentage of microsilica in specimens.
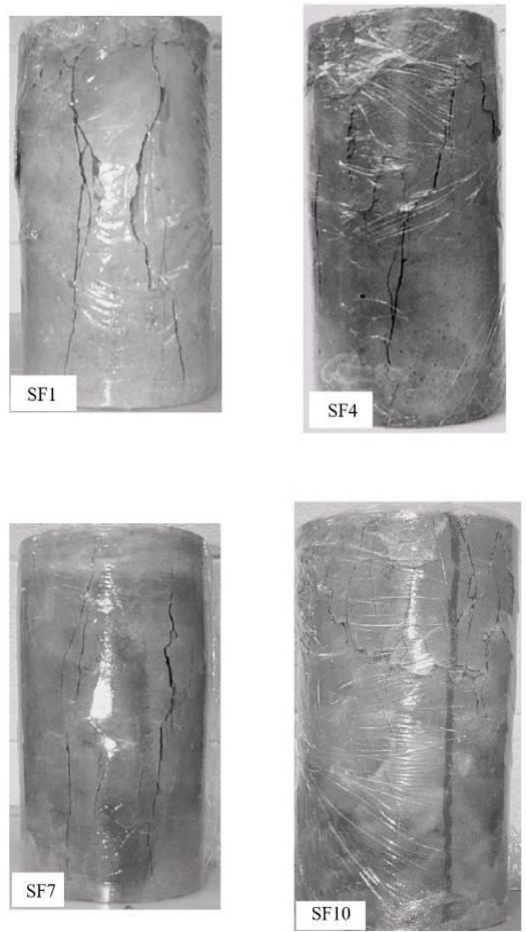

Figure 12. Compressive-shear fracture in laboratory specimens
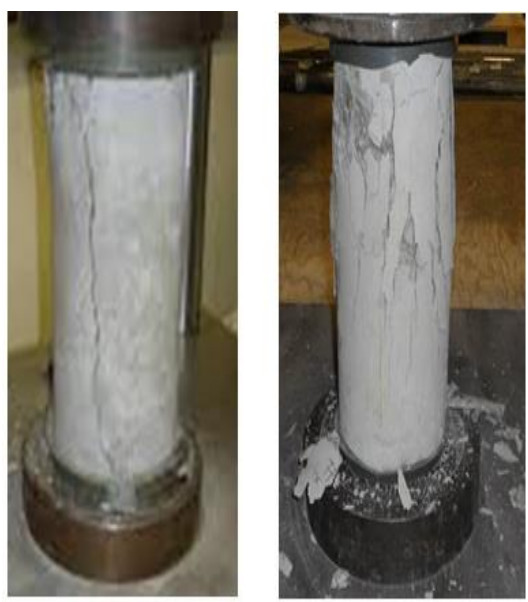

Figure 13. Uniaxial compressive test of cylindrical specimens

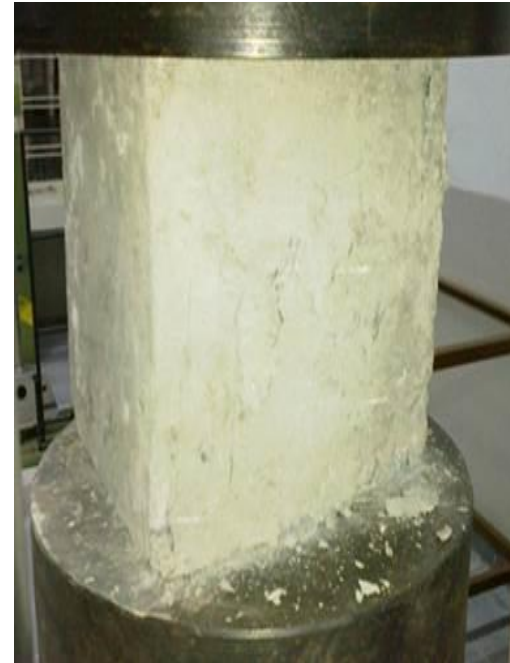

Figure 14. Uniaxial compressive test of cubic specimens

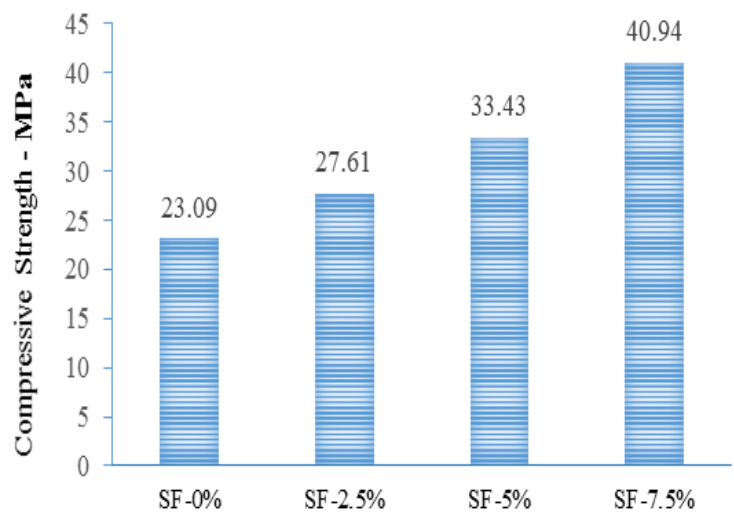

Figure 15. Concrete compression strength versus the percentage of microsilica in specimens

It should be noted that cubic specimens have been used as laboratory initial test specimens, for mix design selection and results verification. The tensile and compressive strengths are based on the data obtained from the results of cylindrical specimens.

Considerable researches have been carried out on the effect of microsilica on the strength and other properties of concrete compared to the effect of cement. The effective factors are:

1. The amount of cement

2. Chemical composition of cement and its fine particles

3. Fineness modulus of sand

4. The proportion of sand to all aggregates

5. Type and amount of plasticizer

6. Temperature

Furthermore depending on the age of concrete strength measurement or desired strength parameter, the effective factor can be changed. Microsilica concrete has been used in slabs, bridge decks, airport floor construction, parking lots and erosion environments so far. 


\subsection{Slump test}

Slump is one of the most important parameters in the measurement of compressive strength because it is indicative of water cement ratio. However, the effect of microsilica on this important parameter has not been investigated so far. In this research, this issue has been considered and the obtained results have been presented in Figure 16.

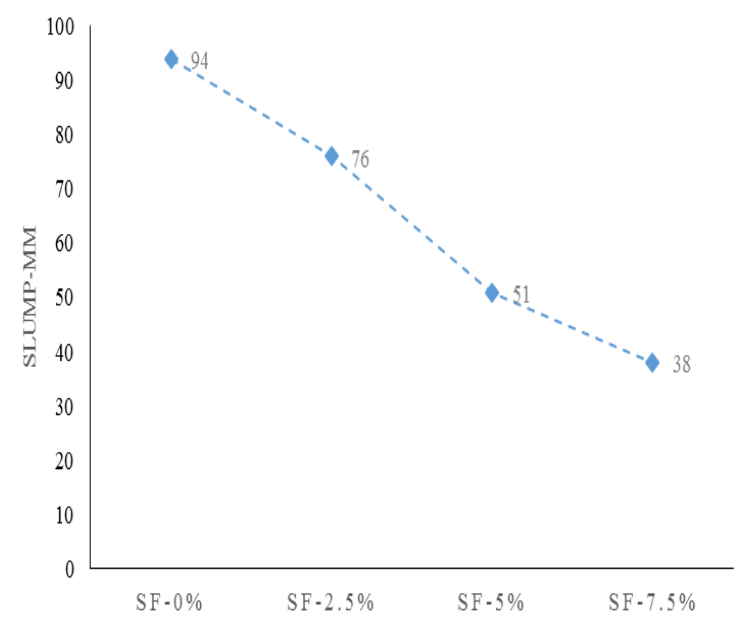

Figure 16. The effect of microsilica on fresh concrete slump

Researches show that microsilica reduces the slump and required water for concrete. Usually the relationship between the amount of water required to maintain the desired slump and the amount of microsilica added to the mixture is almost linear. If microsilica is used alone, it will negatively affect the workability of fresh concrete and will reduce its consistency. Thus, the amount of mixing water should be increased to restore the consistency to ordinary concrete state. While, if microsilica is used in conjunction with plasticizers, the fine and spherical particles of microsilica will disperse among the cement particles and like shots, will help the aggregates to move on each other and will increase the consistency of mixture. Superplasticizers are organic products or a combination of organic and nonorganic materials. These materials have a surface-absorbing property with surface-activator admixtures which mostly include sulfonated melamine or naphthalene formaldehyde. These materials may have retarding, accelerating or foaming properties. It should be noted that the use of Superplasticizers in concrete mixtures containing microsilica is essential because the successful use of microsilica is achieved only when these materials are distributed at the surface of concrete.

\subsection{Setting Time}

Adding up to $5 \%$ of microsilica by weight of cement does not have a significant effect on the setting time of concrete. However, higher quantities retard the setting of concrete up to 40 minutes that means the increase in setting time. Since microsilica replaces with part of cement, reduces the initial hardening strength.

The ambient temperature has a significant effect in this case. In general, high temperature causes an increase in the hydration temperature of cementitious materials which will result in a reduction in the setting time. In other words, the retardation of setting time will be less at high ambient temperatures.

\subsection{Concrete Bleeding}

Microsilica controls the bleeding phenomenon and accelerates the finishing of concrete. However, it increases the risk of plastic shrinkage cracking especially in hot and dry areas.

In the absence of microsilica, the finest particles of concrete are Portland cement particles. They usually have a size of up to 80 $\mu \mathrm{m}$. Since the coarse and fine aggregates are much larger than cement particles, cement particles as stabilizers reduce the size of capillary tubes, which water reaches to the concrete surface along them. When microsilica particles are added to the concrete, the size of capillary tubes is greatly reduced because these particles are able to find their way to the voids and spaces between cement particles which causes fragmentation of water flow channels.

Also, by increasing the number of contact points of the paste particles due to the mentioned performance, the adhesion of the concrete mixture increases significantly. From another point of view, the retarding effect of plasticizers will provide sufficient time for bleeding, so the bleeding is retarded and reduced in microsilica concrete.

\subsection{Shrinkage}

Due to the high evaporation of surface water of concrete in hot and dry weather, the cracks caused by this phenomenon are appeared. Shrinkage in microsilica concrete is less than ordinary concrete. It probably occurs in the early ages (one to seven days) of concrete.

Shrinkage has a linear relationship with the free water in concrete mixture. Increasing the curing time of concrete from one day to fourteen days at 20 degrees centigrade has led to a decrease in the Shrinkage of high strength concrete.

Shrinkage is important for microsilica concretes. Special care is essential to ensure that internal moisture is not quickly lost, otherwise the pozzolanic activity is not performed.

\section{CONCLUSION}

By examining the results of tests on concrete specimens with different percentages of microsilica, it was observed that, regardless of the different percentages of microsilica, the results at the age of 28 days were more reliable than the results at the age of 7 and 14 days. Therefore, the research was based on the age of 28 days results of specimens. All concrete specimens containing microsilica have more strengths compared to concrete specimens without microsilica. The increase in strength was about $8 \%$ for every $2.5 \%$ increase in the amount of microsilica. Microsilica as a complementary component plays a fundamental role in strength increasing in light concrete and improving its other properties. Microsilica, with very fine particles and considerable pozzolanic activity on chemical reactions with calcium hydroxide, reduces the porosity and permeability and increases the durability and strength of 
concrete. The addition of microsilica to concrete reduces its workability. Using an appropriate amount of superplasticizer improves the workability and increases the uniformity of concrete texture, however, the plasticizer should be carefully selected and consumed.

Adding up to $5 \%$ of microsilica by weight of cement does not have a significant effect on the setting time of concrete. However, higher quantities retard the setting of concrete up to 40 minutes that means the increase in setting time. Since microsilica replaces with part of cement, the initial hardening strength reduces. Researches (Investigations) show that microsilica reduces the slump and required water for concrete. Usually the relationship between the amount of water required to maintain the desired slump and the amount of microsilica added to the mixture is almost linear. If microsilica is used alone, it will negatively affect the workability of fresh concrete and will reduce its consistency. Thus the amount of mixing water should be increased to restore the consistency to ordinary concrete state. While, if microsilica is used in conjunction with plasticizers, the fine and spherical particles of microsilica will disperse among the cement particles and like shots, will help the aggregates to move on each other and will increase the consistency of mixture. Superplasticizers are organic products or a combination of organic and non-organic materials. These materials have a surface-absorbing property with surfaceactivator admixtures which mostly include sulfonated melamine or naphthalene formaldehyde. These materials may have retarding, accelerating or foaming properties. It should be noted that the use of Superplasticizers in concrete mixtures containing microsilica is essential because the successful use of microsilica is achieved only when these materials are distributed at the surface of concrete.

\section{REFERENCES}

Genadij, Sh. and Juris, B. "Concrete mix design \& Optimazation”, 2nd Int. Ph.D. Symp. in Civil Eng., Budapest, (1998).

Rahmani, K., Ghaemian, M. and Hosseini, A. "Experimental study of the effect of water to cement ratio on mechanical and durability properties of Nano-silica concretes with Polypropylene fibers" Scientia Iranica, In Press, (2018).

Newlon, H.H.Jr. "Long - Term performance of concrete containing hydrated hydraulic lime as an admixture", In Virginia Highway \& Transportation Research Council, United States, Federal Highway Administration, (1976).

Mehta, P.K. "Concrete in the marine environment", In Elsevier Applied Science, London and New York, (1991).

Kwan, A.K.H. and Mora, C. F. "Effect of various shape parameters on packing of aggregate particles", Mag. of Conc. Res., 53(2), pp. 91-100, (2001).
Carter, R.M. and Yan, Y. "Measurement of particle shape using digital imaging echniques" J. of Phy.: Conf. Ser., pp. 177-182, (2005).

Lee, S.T., Moon, H.Y. and Swamy, R.N. "Sulfate attack and role of silica fume in resisting strength loss" Cem. and Conc. Comp., 27(1), pp. 65-76, (2005).

Torii, K. and Kawamura, M. "Effects of fly ash and silica fume on the resistance of mortar to sulfuric acid and sulfate attack" Cem. and Conc. Res., 24(2), pp. 361-370, (1994).

Faleschini, F., Zanini, M.A., Brunelli, K. and Pellegrino, C. "Valorization of co-combustion fly ash in concrete production", Mat. and Des., 85, pp. 687-694, (2015).

Ferrándiz-Mas, V., Sarabia, L.A., Ortiz, M.C., Cheeseman, C.R. and García-Alcocel, E. "Design of bespoke lightweight cement mortars containing waste expanded polystyrene by experimental statistical methods", Mat. and Des., 89, pp. 901-912, (2016).

Mármol, G., Savastano, H., Tashima, M. M. and Provis, J.L. "Optimization of the MgOSiO2 binding system for fiber-cement production with cellulosic reinforcing elements", Mat. and Des., 105, pp. 251-261, (2016).

Zhang, P. and Li, Q.-F. "Combined Effect of Silica Fume and Polypropylene Fiberon Drying Shrinkage Properties of Concrete Composites Containing Fly Ash", Scientia Iranica, 20(5), pp. 1372-1380, (2013).

Mirsayar, M., Shi, X., Zollinger, D. "Evaluation of interfacial bond strength between Portland cement concrete and asphalt concrete layers using bi-material SCB test specimen", Eng. Solid Mech., 5(4), pp. 293-306, (2017).

Jafari, Kh., Tabatabaeian, M., Joshaghani, A. and Ozbakkaloglu, T. "Optimizing the mixture design of polymer concrete: An experimental investigation", Const. and Build. Materials, 167, pp. 185-196, (2018).

Unterweger, C., Brüggemann, O. and Fürst, C. "Effects of different fibers on the properties of short-fiber-reinforced polypropylene composites", Combust. Sci. Technol., 13, pp. 49-55 (2014).

Unterweger, C., Brüggemann, O. and Fürst, C. "Synthetic fibers and thermoplastic short-fiber-reinforced polymers: properties and characterization", Polym. Compos., 35, pp. 227-236 (2014).

Ozawa, M. and Morimoto, H. "Effects of various fibres on hightemperature spalling in high-performance concrete", Constr. and Build. Mater., 71, pp. 83-92, (2014).

Kodur, V. "Properties of concrete at elevated temperatures", ISRN Civ. Eng., 2014, pp. 1-15, (2014).

Rahmanzadeh, B., Rahmani, K. and Piroti, S. "Experimental study of the effect of water-cement ratio on compressive 
strength, abrasion resistance, porosity and permeability of Nano silica concrete", Frattura ed Integrità Strutturale, 44, pp. 1624, (2018).

Yazıc1, H. "The effect of silica fume and high-volume Class C fly ash on mechanical properties, chloride penetration and freeze-thaw resistance of self-compacting concrete" Constr. and Build. Mater., 22(4), pp. 456-462, (2008).

Song, H.W., Jang, J.W., Saraswathy, V. and Byun, K.J. "An estimation of the diffusivity of silica fume concrete" Build. and Environ., 42(3), pp. 1358-1367, (2007). 